\title{
Indirect restoration in composite resin: a clinical report of self-adhesive cementation in deproteinized dentin
}

\begin{abstract}
The use of direct composite resin in restorations is the most common method of rehabilitation. However, its indication becomes critical when the rehabilitation occurs in teeth with wide structural involvement. In such indirect restorations, either partial or total, offers the best aesthetic and functional performance. How to proceed in such situations where there are impossibilities to accomplish this treatment due to high costs of laboratorial steps without losing the aesthetic excellence? This study aims to report and discuss clinical steps to making a indirect restoration in composite resin accomplished in a endodontically treated teeth. It was used contemporary adhesive techniques (deproteination + self-adhesive cementation). The patient J. A. S., 17 years was identified with a wide temporary restoration on teeth 36 . Thinking of financial condition of the patient, who did not have real conditions to pay an allceramic restoration, it was planned an indirect restoration using composite resin with an installation of a root retainer of fiberglass. The clinical steps were: root desobturation; acid etching with phosphoric acid; use of $2.5 \%$ sodium hypochlorite solution; post's cementation using self-adhesive cement with previous application of silano; confection of temporary material; laboratorial step to produce the restoration; cementation of restoration. The case obtained an excellent aesthetic and functional result and the indirect restoration in composite resin became an affordable option.
\end{abstract}

Volume 10 Issue I - 2019

\author{
Mário Pedro Vasconcelos Bezerra Silva,' \\ Fábio Barbosa de Souza ${ }^{2}$ \\ 'Dental School, Federal University of Pernambuco, Brazil \\ ${ }^{2}$ Department of Prosthodontics and Oral Facial Surgery, Federal \\ University of Pernambuco, Brazil
}

Correspondence: Fábio Barbosa de Souza, Federal University of Pernambuco, Department of Prosthodontics and Oral Facial Surgery, Av. Prof. Moraes Rego s/n, Cidade Universitária, RecifePE, CEP, 50670-90I, Brazil, Tel +55-8I-2 I26-8830, +55-8I-99748237, Fax +55-8I-2I 26-8344, Email fabiobdsouza@gmail.com

Received: January II, 2019 | Published: January 23, 2019

Keywords: permanent dental restoration, composite resin, sodium hypochlorite, post and core technique

\section{Introduction}

Direct restorations in composite resin represent the most common method of dental rehabilitation. However, the posterior region has some complications and limitations to perform this technique: polymerization contraction, postoperative sensitivity, adhesive failures, wear. ${ }^{1}$ These drawbacks become more critical when rehabilitation occurs in heavily destroyed teeth, situations in which the indirect technique is the most indicated. ${ }^{2}$ The cases with great structural impairment, which previously were only solved with invasive prosthetic treatments and of high cost, today can be solved perfectly with minimally invasive techniques. In this sense, the latest generation composite resins can be used indirectly, thus facilitating access to people who cannot afford the laboratorial costs. ${ }^{3}$ In general, indirect resinous restorations have a number of advantages, such as: greater longevity when compared to direct restorations; possibilities for repair; adjustment and intra-buccal polishing. ${ }^{4}$ These indirect composite restorations are a great alternative for large restorations of posterior teeth. The scientific literature has evidenced numerous reports of clinical success cases when using this technique..$^{5-9}$ Another aspect to be considered corresponds to the annulment of the nutritive pulp support after the endodontic treatment, a common situation in the teeth with indication for indirect restorations. This condition may result in a weakened dentin protein framework in which the performance of conventional adhesive techniques could culminate in early bond failure due to the susceptibility of this collagen fiber network. To overcome this limitation, some studies have pointed to dentin deproteinization as one of the possible strategies for the optimization of adhesion, especially when the self-adhesive cements are used, which do not require previous dental pre-treatment, simplifying the cementation steps. ${ }^{10-12}$
With the development of resin-based cements, the limited mechanical properties and relatively high solubility in the oral environment presented by traditional cements, such as polycarboxylate, zinc phosphate and zinc oxide eugenol, are being softened. ${ }^{13}$ Clinical reports involving the dissolution of dentinal collagen fibers in association with adhesive cementation, which demonstrates the importance of a detailed description of the clinical stages, aiming at greater dissemination to the scientific community. The aim of this study was to describe, through a case report, the steps for the preparation of an indirect restoration in composite resin, performed on an endodontically treated tooth, using contemporary union techniques (deproteinization+self-adhesive cementation).

\section{Case report}

A 17-year-old female patient, melanoderma, sought the Center for Reception and Emergency Care at the Dental School of the Federal University of Pernambuco (Recife, Brazil). The main complaint was restricted to the need for rehabilitation of a posterior tooth submitted to recent endodontic treatment. The anamnesis indicated absence of painful symptomatology associated to the tooth in question. After physical and radiographic examinations, there was a coronary structural loss of more than $50 \%$, with healthy or adequately restored teeth, as well as absence of radiolucent images suggestive of periapical lesion (Figure 1). The treatment plan indicated an indirect restoration in composite resin using self-adhesive cement for fixation, associated with the technique of dentin deproteinization. The need to use an intracanal fiber glass post was also observed.

Initially, under relative isolation, the temporary restorative material and remaining carious tissue were removed with spherical diamond tips (KG Sorensen) (Figure 2A). The great structural loss 
indicated the need for a pin installation, whose technique started with the partial desobturation of the distal canal with the use of Largo-type drills compatible with the root canal (Figure 2B). After radiographic confirmation of the desobturation at a depth corresponding to $2 / 3$ of the root canal with bone support, post was selected by comparing the root with the radiographic image. Number 2 retainer (White Post, FGM) was chosen as more compatible. Subsequently, it was performed: demarcation of the post (Figure 2C), allowing a distance of $2 \mathrm{~mm}$ in relation to the occlusal surface; cutting of the retainer with cylindrical diamond tip, under refrigeration; application of $37 \%$ phosphoric acid for 15 seconds for performing a surface cleaning; washing with water for 15 seconds; drying; silane application for 60 seconds; drying; bonding agent application (Single Bond 2/3M ESPE); drying and photoactivation for 15 seconds.

To prepare the tooth, it was performed under absolute isolation: prophylaxis with pumice and water paste (Figure 3A); application of $37 \%$ phosphoric acid for 15 seconds on all intracanal and coronary dentin surfaces (Figure 3B); washing with water for 15 seconds; drying with cotton swabs and absorbent paper cones; application of $5 \%$ sodium hypochlorite for 4 minutes (Figure 3C); wash with water for 2 minutes; drying.

Post cementation was performed: manipulation and insertion of the RelyX U200 self-adhesive resin cement (3M ESPE) inside the canal with modified exploratory probe; placing cement on the surface of the retainer; adaptation of the post in the root canal; removal of excess cement; photoactivation for 20 seconds (Figure 4A). The Adper Single Bond 2 bonding agent (Figure 4B) was applied. It was decided to fill with composite resin (Filtek Z350 XT-3M ESPE), applying the composite in increments, already simulating the expulsive conformation and shape of the core to be obtained after preparation (Figure 4C). The preparation was performed with diamond tip 3131 (KG Sorensen), in order to obtain smooth surfaces and able to make the walls expulsive.

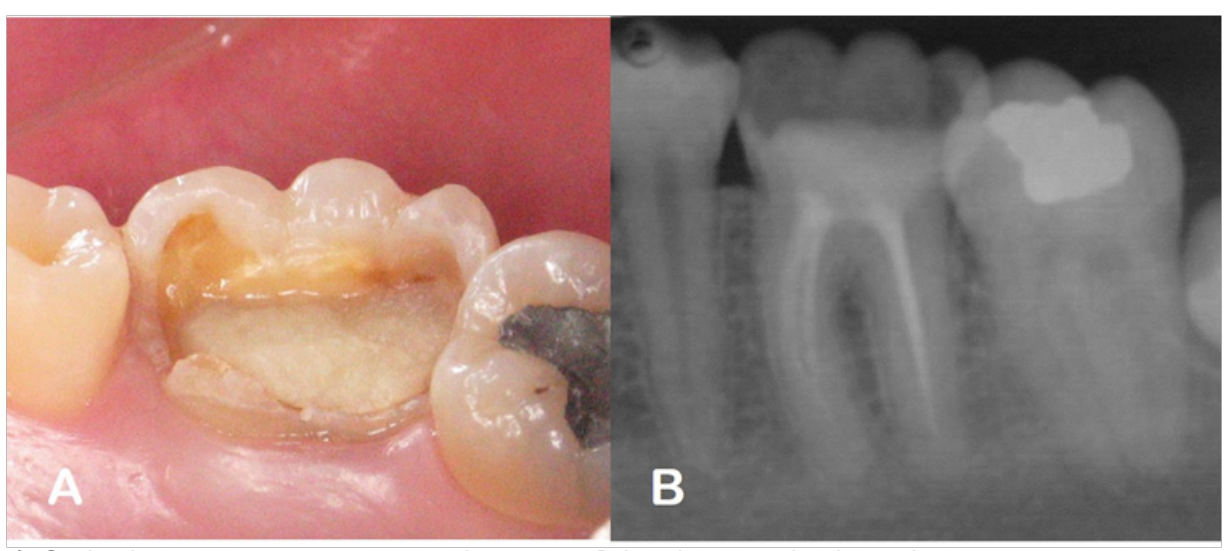

Figure I Case diagnosis.A: Occlusal vision - extensive coronary destruction; B: Initial periapical radiography.

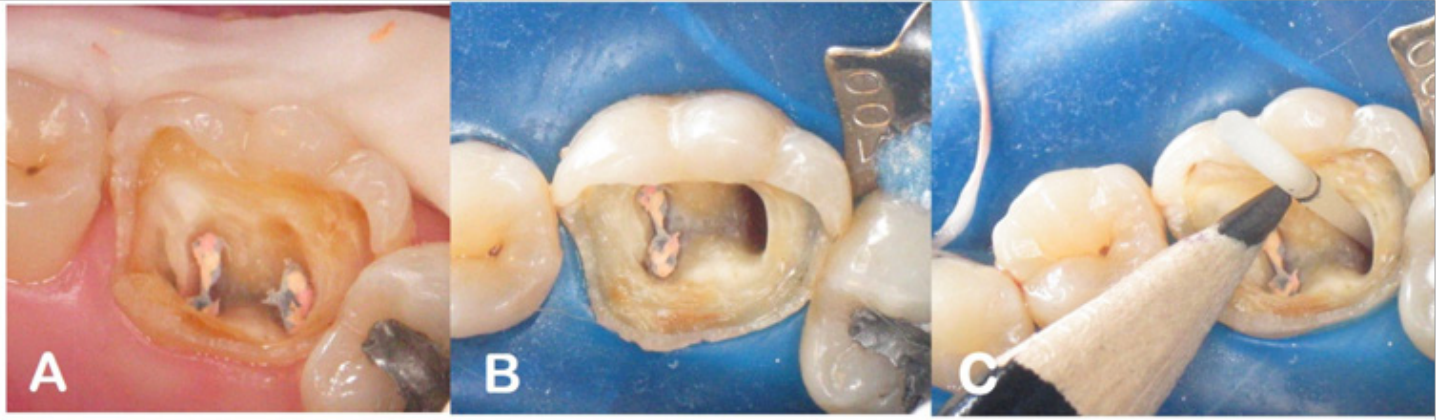

Figure 2 A: Dental remnant after removal of temporary restoration; B: Root canal after desobturation; C: Post demarcation for further cutting.

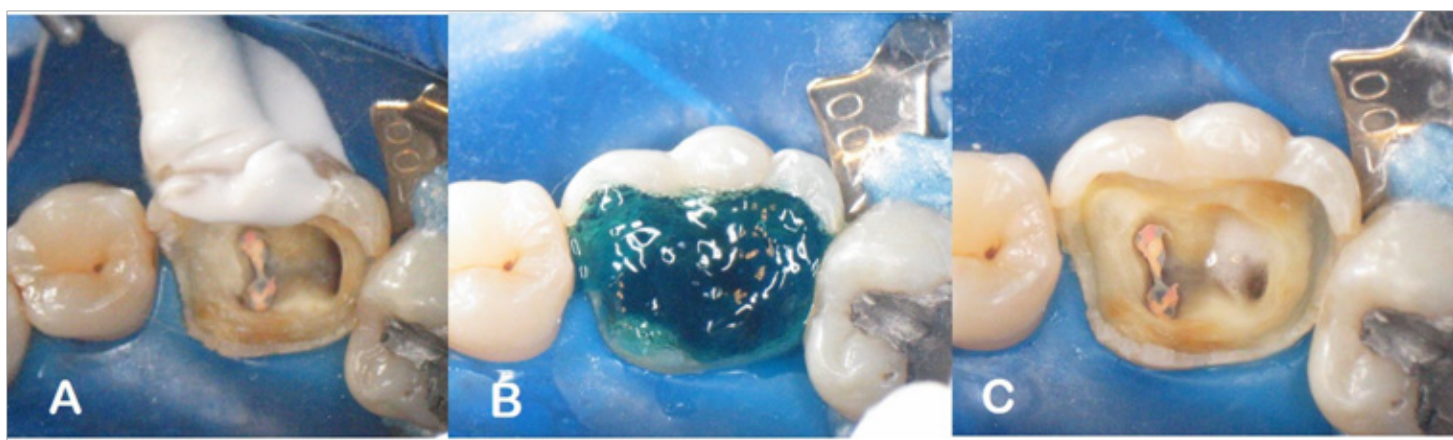

Figure 3 A: Prophylaxis with pumice and water paste; B: Conditioning H3PO4 - 37\%; C: Deproteinization with 2.5\% NaOCl (4 minutes). 
The partial molding procedure with addition silicone (Express $\mathrm{XT} / 3 \mathrm{M}$ ESPE) was performed in the upper and lower hemi-arcades. The occlusion was recorded with the dense silicone material. The provisional restoration was made with resin - based material (Bioplic - Biodynamics). After assembly of the models in verticulator (Figure $5 \mathrm{~A}$ ), restoration was made by the stratification technique (Figures $5 \mathrm{~B}$ $\& 5 C)$. Restoration was packed in surgical grade paper and submitted to an autoclave sterilization cycle (Figure 5D). Finishing and polishing were performed with Soflex Pop-on disks (3M/ESPE) and rubber tips associated with polishing paste composites (Figures 5E), resulting in polished and natural looking surfaces (Figures 5F).
At final consultation, provisional removal and adjustment of the restoration were made. The inner face of the restoration was cleaned with $37 \%$ phosphoric acid for 15 seconds, followed by washing for 30 seconds and drying with air jets. Cementation stage was then started, which was started with prophylaxis with pumice and water slurry, washing and drying of the surfaces. The self - adhesive resin cement (Rely X U200-3M/ESPE) was inserted into the internal restoration face, which was adapted to the tooth. After the excesses were removed, photoactivation was performed for 20 seconds on each face of the restorations, resulting in restoration of tooth shape and esthetics (Figure 6).

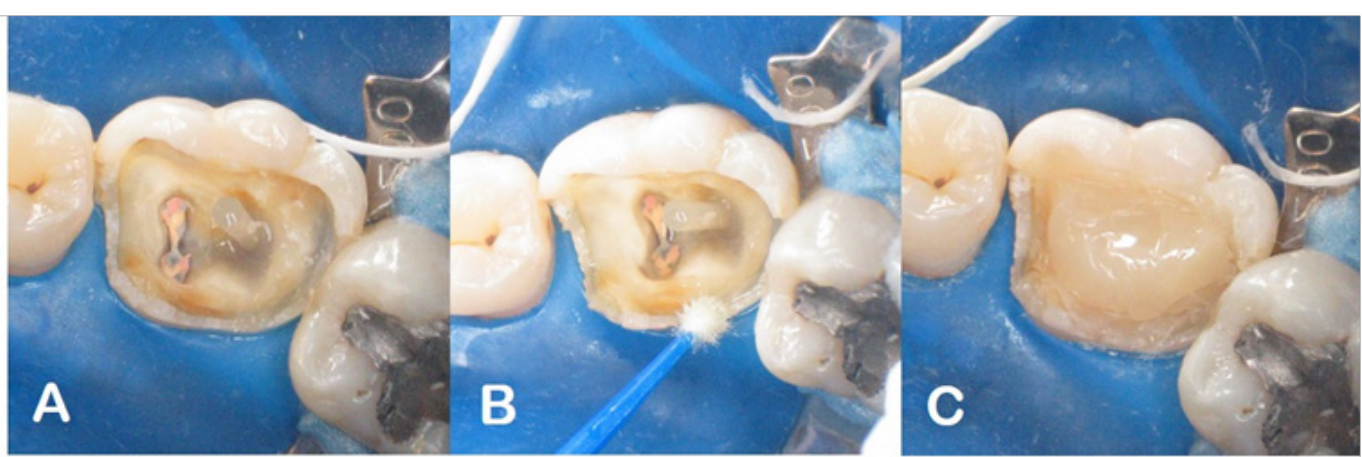

Figure 4 A: Cemented fiberglass post; B:Application of Adper Single Bond Bonding Agent 2-3M ESPE; C: Preparation of the filling core (Filtek Z350 XT - 3 M ESPE).
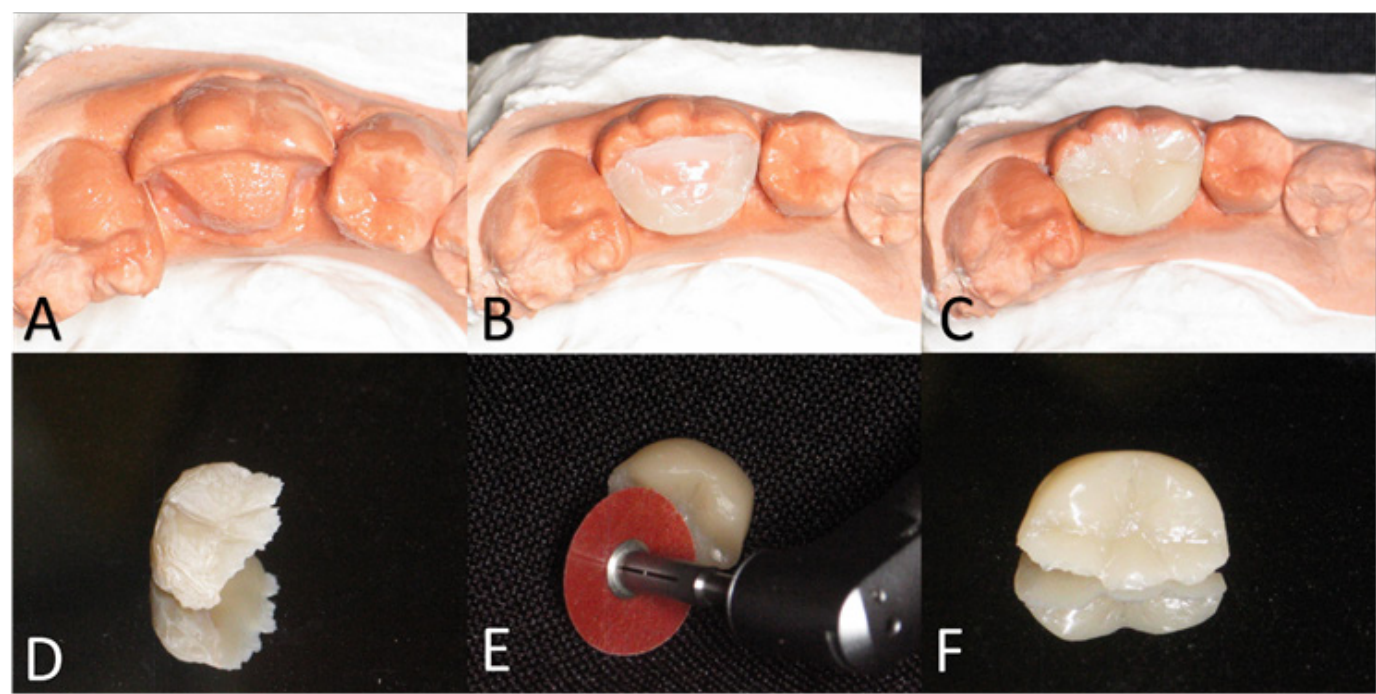

Figure 5 A: Model for making the indirect restoration; B: Execution of indirect restoration; C: Indirect restoration completed; D: Restoration after autoclave cycle; E: Finishing the piece (Sof-Lex Pop On - 3M ESPE); F: Restoration with proper finishing and polishing, ready for cementation.

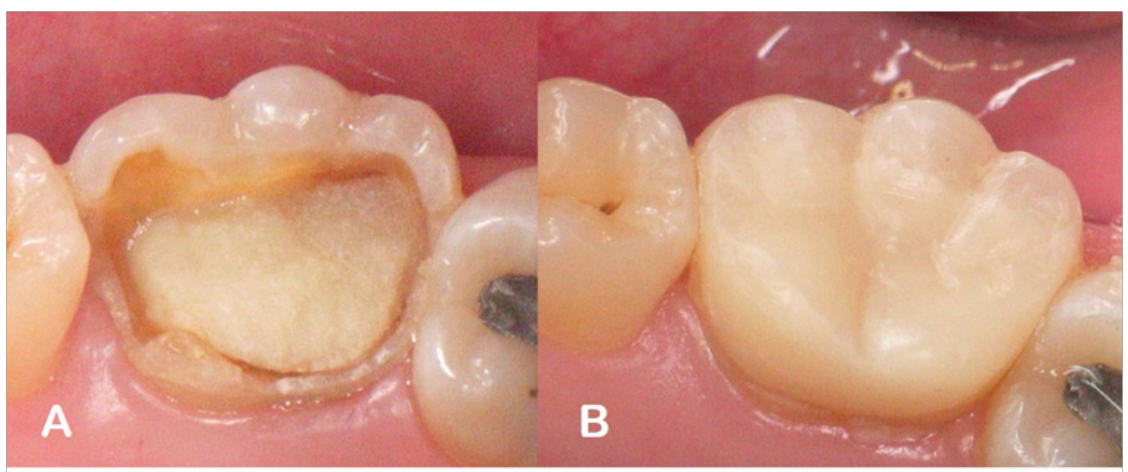

Figure 6 A: Initial aspect; B: Final appearance. 


\section{Discussion}

Socioeconomic status is a decisive factor during the rehabilitation planning phase in widely compromised teeth. In these cases, the majority of treatment options involve the use of high cost materials, generally associated with the need to use laboratory resources to make indirect restorations. Thus, since the patient in this case did not have the conditions to pay the laboratorial costs, it was decided to perform the composite resin restoration by the indirect technique. As a rule, the aesthetic material of choice for making indirect restorations is often ceramic. However, due to the high cost, its use is limited to patients with financial conditions to bear the costs of treatment. Consequently, the possibility of using the composite resin indirectly as an alternative to ceramics appears. ${ }^{14}$

Besides the financial question, ease of handling places the composite resin as a material of preference for the indirect technique. ${ }^{15}$ In this sense, the ease of restoration of the proximal and occlusal contours makes the technique quite attractive. ${ }^{16}$ Despite these advantages, restoration of posterior teeth places occlusal stress and possibility of fracture and/or wear as a point of concern when indicating composites as indirect materials. The response to this questioning arises from the results of clinical trials, which have demonstrated excellent longevity, good marginal adaptation and low incidence of secondary caries lesions for indirect composite resin reconstruction..$^{5-9}$ In a study conducted by Huth et al., ${ }^{5}$ In which indirect restorations were performed with two resin-based materials-Artglass/Haerous Kulzer \& Charisma/Haerous Kulzer-excellent performance with respect to wear at $100 \%$ and $96 \%$ of restorations, respectively, after 4 years of evaluation. According to Peutzfeldt and Asmussen, ${ }^{17}$ the possibility of photoactivation for a longer time, outside the buccal cavity, would be able to optimize the physic and mechanical properties of the restoration, consequently increasing the resistance to wear.

Another factor that has provided improvement of the mechanical properties of the resins is the use of post-photoactivation heat, ${ }^{18}$ which in this case was represented by the restoration submission to an autoclave cycle. This clinical action allows a complementary polymerization by heat, capable of increasing the degree of conversion of restorative composites. In the manufacture of indirect restorations with composite resins, the heat treatment performed after light polymerization increases the monomer conversion of the material. This increase would not be possible when only photoactivation was used. The surface hardness of a composite resin is dependent on the type of inorganic filler, but shows correlation with the degree of conversion, serving as a method that reflects the physical properties of the composites. The higher the hardness, the better the mechanical properties of the material. ${ }^{19,20}$ Greater polymerization results in a material of better chemical and color stability, because the lower the chances that pigment or oxygen molecules will bind to free carbon radicals. Furthermore, during the heat-polymerization process, there is an evaporation of about $1.3 \%$ of the organic portion of the matrix and a decrease in the release of free monomers, providing a material with fewer constituents of poorer properties and with greater biocompatibility, since free monomers are acidic substances and toxic to living tissues. ${ }^{21}$

Exceeding the physic and mechanical characteristics of the material, its retention should also be discussed, especially in endodontically treated teeth with great structural impairment. These teeth are historically considered as a challenging clinical situation in dentistry. In this situation, the tooth loses elasticity, and by the loss of its structure becomes rigid and more susceptible to fractures. Over time, it was observed that the use of metal cores was no longer a viable option for many of these cases, due to the absence of adhesion, possibility of corrosion and high modulus of elasticity. ${ }^{22,23}$ The prefabricated posts, on the other side, such as those of fiberglass used in the clinical case, were developed to replace in some situations the cast posts and also the prefabricated metal cores. The modulus of elasticity of the fiberglass posts is more similar to dentin, to the resin cement used to fix the post to the tooth and the composite resin to the filling, qualifying it for clinical use. Consequently, the root fracture of teeth restored with glass fiber is smaller, when compared to those restored with ceramic and metallic cast posts, due to the better distribution of forces in this system. ${ }^{24}$

The adhesion of the posts to the root dentine has also been a critical point for the fixation of the intracanal retainers, and the complete inadaptation of adhesive posts is one of the main post-cementation faults, due to the complexity of the root adhesion. ${ }^{25,26}$ Scientific evidence has shown that the degradation of the collagen fibrils may lead to deterioration of the hybrid layer. As a consequence, this may lead to compromising the durability of adhesion in the long term. ${ }^{3}$ Taking this possibility into account, the deproteinization technique was used to make the hybrid layer more stable and reduce its degradation process. In this technique, the dissolution of the collagen fibers occurs, due to the non-specific proteolytic action of the sodium hypochlorite, generating a differentiated dentin substrate and, consequently, improving the adhesion of the restoration. ${ }^{27}$ The scientific literature has evidenced that the surfaces that underwent the deproteinization process have presented dentinal tubules with enlarged opening, exposing innumerous smaller holes in the intertubular dentine. This large porosity would be able to increase the permeability, offering a more receptive substrate to the cementation systems. ${ }^{10,11}$

As the clinical success of indirect restorative procedures depends on the fixation technique used, the choice of cement plays a fundamental role for clinical longevity. The choice of self-adhesive cementation was based on the simplicity of application, which could overcome the sensitivity of the inherent technique to multi-step cementitious systems..$^{28}$ As self-adhesive cements have limited adhesion capacity, associations with deproteinizing denture pretreatment have shown promising results. ${ }^{10-12}$ Finally, in order to know when and how to perform indirect restoration, the professional must have a broad theoretical and clinical knowledge in order to understand that a good restoration is not only done taking into account the ability of the person who will perform the restoration. In many cases, no matter how good the professional, the technique most appropriate to the situation is what will make the difference.

\section{Conclusion}

The preparation of an indirect restoration in composite resin, performed on an endodontically treated tooth, using contemporary joint techniques (deproteinization + self-adhesive cementation) proved to be effective, not only in the aesthetic aspect, but mainly functional, restoring to the patient the joy and confidence in having back the correct chewing. Thus, using the composite resin as a material for making indirect restoration due to the socioeconomic aspect was an excellent alternative, scientifically based.

\section{Acknowledgments}

None. 


\section{Conflicts of interest}

The authors declare that there are no conflicts of interest.

\section{References}

1. Higashi C, Arita C, Gomes JC, et al. Estágio atual das resinas indiretas. Pro-odonto Estética: SESCAD, Curitiba. 2012:1-48.

2. Felippe LA, Baratieri LN, Mateiro S, et al. Restaurações indiretas em posteriores com Inlays e Onlays de Resina Composta. $R G O$ 2002;50(4):231-236.

3. Barbosa De Souza F, Sinclér Delfino C, Lacalle Turbino M, et al Deproteinized dentin: a favorable substrate to self-bonding resin cements? J Biomed Mater Res B Appl Biomater. 2011;98(2):387-394.

4. Souza GMD, Pereira GD, Paulillo LAMS. Evolution of composite resin: literature review. $J B C$. 2003;2:141-147.

5. Huth KC, Chen HY, Mehl A, et al. Clinical study of indirect composite resin inlays in posterior stress-bearing cavities placed by dental students: Results after 4 years. J Dent. 2011;39(7):478-488.

6. Jongsma LA, Kleverlaan CJ, Feilzer AJ. Clinical success and survival of indirect resin composite crowns: Results of a 3-year prospective study. Dental Materials. 2012;28(9):952-960.

7. Ozakar-Ilday N, Zorba YO, Yildiz M, et al. Three-year clinical performance of two indirect composite inlays compared to direct composite restorations. Med Oral Patol Oral Cir Bucal. 2013;18(3):e521-e528.

8. Alharbi A, Rocca GT, Dietschi D, et al Semidirect composite onlay with cavity sealing: a review of clinical procedures. $J$ Esthet Restor Dent. 2014;26(2):97-106.

9. Nicola B, Alessandro P, Michele V, et al. Indirect composite restorations luted with two different procedures: A ten years follow up clinical trial. J Clin Exp Dent. 2015;7(1):e54-59.

10. Xia Y, Cheng XJ. Effect of different pretreatments to post-space on bonding strength of fiber posts luted with a self-adhesive resin cement. J Wuhan Univ Technol.-Mat Sci Edit. 2013;28(5):984-989.

11. Lisboa DS, Santos SV Griza S, et al. Dentin deproteinization effect on bond strength of self-adhesive resin cements. Braz Oral Res. 2013;27(1):73-75.

12. Faria-e-Silva AL, Menezes MS, Silva FP, et al. Intra-radicular dentin treatments and retention of fiber posts with self-adhesive resin cements. Braz Oral Res. 2013;27(1):14-19.

13. Guedes LLS, Mattos ECG, Zani IM, et al. Mechanical properties evaluation of conventional and self-etching resin cements. Rev Odontol UNESP. 2008;37(1):85-89.
14. Lago M, Skupien JA, Souza NC. Indirect restorations in composite resin - demystification of the technique. Int J Dent. 2011;10(4):282-286.

15. Burke FJT, Qualtrough AJE. Aesthetic inlays: composite or ceramic. $\mathrm{Br}$ Dent J. 1994;176(2):53-60.

16. Dijken JWV. Direct resin composite inlays/onlays: an 11 year followup. J Dent. 2000;28(5):299-306.

17. Peutzfeld A, Asmussen E. Mechanical properties of the composites resins for the inlay/onlay technique. J Prosthet Dent. 1991;66(3):322-324.

18. McCabe JF, Kagi S. Mechanical properties of a composite inlay material following post-curing. British Dental Journal. 1991;171(8):246-248.

19. Arossi GA, Ogilari F, Samuel SMW, et al. Polimerização complementar em autoclave, microondas e estufa de um compósito restaurador direto. Rev Odonto Ciênc- Fac. Odonto/PUCRS. 2007;22(56):177-180.

20. Silva CHV, Filho PFM, Souza FB, et al. Restauração Indireta em Resina Composta: uso do calor na polimerização adicional. Odontol clín cient. 2007;6(1):85-89.

21. Yap AUJ, Lee HK, Sabapathy R. Release of methacrilic acid from dental composite. Dent Mater. 2000;16:172-179.

22. Dilmener F, Sipahi C, Dalkiz M. Resistance of three new esthetic postand-core systems to compressive loading. J Prosth Dent. 2006;95(2):130-136.

23. Quintas A, Bottino M, Neisser M, et al. Effect of the surface treatmen of plain carbon fiber posts on the retention of the composite core: an in vitro evaluation. Pesq Odon Bras. 2001;15(1):64-69.

24. Sá TCM, Akaki E, Sá JCM. Pinos estéticos: Qual o melhor sistema? Arqu Brás odontol. 2010;6(3):179-184.

25. Amaral M, Rippe MP, Bergoli CD, et al. Multi-step adhesive cementation versus one-step adhesive cementation: push-out bond strength between fiber post and root dentin before and after mechanical cycling. Gen Dent. 2011;59(5):e185-191.

26. Faria e Silva AL, Casselli DS, Ambrosano GM, et al. Effect of the adhesive application mode and fiber post translucency on the pushout bond strength to dentin. J Endod. 2007;33(9):1078-1081.

27. Perdigão J, Thompson JY, Toledano M, et al. An ultramorphological characterization of collagen-depleted etched dentin. Am J Dent. 1999;12(5):250-255.

28. Ferracane JL, Stansbury JW, Burke FJ. Self-adhesive resin cements - chemistry, properties and clinical considerations. J Oral Reabil. 2011;38(4):295-314. 